\title{
Placing Myself in the Picture - An Autobiographical Approach to the Phenomenology of Language, Identity, Trauma and Memory
}

\author{
Fernanda Carrá-Salsberg ${ }^{1}$ \\ York University
}

\begin{abstract}
This brief self-narrative juxtaposes philosophical and psychoanalytic theories of language and trauma with descriptions of the author's experiences as: a child and adolescent migrant, a fragmentary language learner, and a postsecondary language educator. It studies the short and long-term effects of having one's language of identification undervalued by political tensions, and examines what it means for the ego to (re)construct its identity following a language-related emotional crisis. The author defines her libidinal attachments to her introjected tongues and discusses how her present state of being within uneven languages were carved by the memory of her experiences as a child and an adolescent migrant. Similar to Jacques Derrida's (1996) description of "disorders of identity", Carrá-Salsberg blends theory with her recollections of lived occurrences to conceptualize the way in which the inscription of early traumatic occurrences within languages ground subjects' life-long responses and attitude towards their acquired tongues.
\end{abstract}

\section{Introduction}

After writing and re-writing my autobiography, I tried unsuccessfully to gather my thoughts for an introduction to this paper. I attempted to produce a paragraph that would link to my circumstances with language, but encountered nothing short of a brick wall, or as it is said in English, an intense case of writer's block. After hours of frustration and at least seven attempts to what was clearly becoming the prelude to an unsuccessful paper, I decided to take a different approach to writing and began brainstorming with questions relating to my collage of experiences as a migrant and my profound interest in language, desire, repression, identification and trauma. Similar to Freud's intent with Anna O's 'talking cure', I tried overcoming my own resistance by writing questions without knowing if my actions would lead to anything fruitful. I wrote questions such as: What is a repressed language? What does it mean to live between languages? What does my mother tongue mean to me? What does it represent? Under which circumstances do subjects feel at a loss for language? What does it signify to speak, live and house the language of trauma? And at last, what does it mean to live with the oppressor in me? During the very late hours of the night, these questions shed light to my studies, pointing me in the direction of this autobiographical, research paper.

${ }^{1}$ Correspondence concerning this article should be addressed to Dr. Fernanda Carrá-Salsberg, Department of Languages, Literatures and Linguistics, York University, Toronto/Canada. E-mail: fcarra@yorku.ca 


\section{My History within Languages}

From the early twentieth century, political, social, religious, ethnic and economic factors have contributed to the mass emigration of individuals from Spanish speaking countries. Many came to countries like Canada and the United States in search for economic stability, freedom of speech, religious, racial and sexual tolerance. Entire families have left their countries of origin in hopes for new opportunities, a fresh start and a better life. It was a combination of these factors that impacted my parents' decision to immigrate to Ontario, Canada from Buenos Aires, Argentina when I was two years of age. Since neither one of my parents was proficient in the language spoken by the dominant linguistic community, my older sister and I learned English at school. As it is common with most young immigrants, within a relatively short period of time, my sister and I became accustomed to the culture we comfortably attained by means of interactions with teachers, with our newly acquired school friends and neighbours. However, after living in Canada for six years my parents decided to return to our country of origin. My parents' major fears was raising their children in a foreign country and culture they did not understand. Naively believing that the economic and political situation had somewhat improved over the years, my parents decided to take my older sister, my three year-old brother and I from our Canadian surroundings and return to Argentina.

Even though my parents spoke Spanish in our Canadian home, being the second born in the family affected my acquisition and maintenance of Spanish. Throughout my childhood years in Canada I was not fluent in Spanish and had a distinct English accent when attempting to express myself in Spanish. Even though Spanish, and not English, was my mother tongue, as a young child English was the language I lived and breathed. While Spanish, on the other hand, was the language with which I struggled, the language that belonged to my parents and relatives. Back in Argentina, I became driven by an intense desire to become proficient in my mother tongue and to fit-in with my heritage culture. Returning to what felt like a foreign environment was difficult. According to my parents, our second migration was our return 'home'. For me, however, it marked the beginning of my first intra-subjective splitting' ${ }^{2}$ and sense of linguistic and sociogeographical displacement. My alienation and uneasiness was present from my moment of arrival. These feelings increased, moreover, only months following our return when a war broke between Argentina and Great Britain over the Falkland Islands.

Consistent with my experience(s), language, aside from becoming the means of communication, it grants subjects a sense of belonging and identity, or, on the contrary, a sense of otherness and displacement. At the time of my return to Argentina, Buenos Aires was a province populated primarily by second, third and fourth generation immigrants. Consequently, children of my generation were not accustomed to hearing a foreign accent from a fellow classmate. My English accent, combined with the war against an English speaking country, turned me into a victim of bullying and hostility in the schoolyard and neighborhood. English 'grounded my social existence' (Bohorquez, 2008 , p.49). In the eyes of my fellow schoolmates and young neighbours, it embodied my

\footnotetext{
2 'Intrasubjective splitting' is a phenomenological response to subjects' deep-rooted crisis or trauma. This experience is defined as a disorienting fragmentation or split that disrupts individuals' sense of temporal continuity: subjects feel stuck in a never-ending present and are thus unable envision a cohesive future. (Freud, 2006, pp. 137-139; Van der Kolk \& Van der Hart, 1995, pp. 175-176).
}

Language and Psychoanalysis, 2016, 5 (1), 4-13 
presence into that of an enemy.

It is not uncommon for a childhood language to become deactivated by the cessation of such language's use (Pavlenko, 2014, p. 223). When a 'language ceases to be inhabited' (Adorno, 1974, p. 87) by no longer being the tongue of everyday social interactions and inner speech, multilingual subjects often become detached to such symbolic code and inevitably attached to the host tongue of daily -and nightly- function. However, in my case, the abandonment of the English language while in Argentina was not exclusively linked to this symbolic code's lack of instrumental function and social meaning ${ }^{3}$. My detachment of this symbolic code was concurrent with my rejection of a newly constructed foreign identity. When I returned with my parents and siblings to my country of birth, I perceived the distinct English accent that was embedded in my speech as the reason for my daily and nightly torment, my sense of otherness and pain. This traumatic experience within language not only ignited my desire to become proficient in Spanish, it also made me eager to disconnect myself from my unwanted identity as a dominant English speaker.

Language, as the essence of our existence, becomes the receptacle of emotions. It is the vehicle by which we attain and disperse our layered knowledge and construct, deconstruct and reconstruct our identities. A symbolic code forms and informs our belief systems, our perceptions, interpretations and who we believe and are believed to be (Derrida 1996, pp. 10-11). Our language's psycho-emotional and social importance may explain why for many, a negative socio-linguistic experience can easily be turned into the source of a deep-rooted trauma. In Monolingualism of the Other or The Prosthesis of Origen, Jacques Derrida (1996) describes his own past experience with language, identity and trauma. During World War II, as a Franco-Maghrebian child of Jewish decent, the author, along with other members of his Algerian Jewish community, was ostracized, stripped from his French citizenship and his right to attend public school ${ }^{4}$. As explained throughout his autobiographical narrative, since language and social culture are profoundly intertwined (p. 29-53), having his citizenship ablated for a period of two years caused a "disorder of identity" (pp. 16-17, p. 29) which was an alienating confusion that extended to his feeling towards French and his French identity:

I was very young at the time, and I certainly did not understand very well...what

citizenship and loss of citizenship meant to say. But I do not doubt that exclusion-

from the school reserved for French citizens- could have a relationship to the

\footnotetext{
${ }^{3}$ In this paper, a language's social meaning is tied to its ability to become a vehicle for communication within a dominant linguistic community.

${ }^{4}$ Derrida (1996) emphasis that the removal of citizenship did not occur under 'the Occupation': “It was a Franco-French operation, one even ought to say an act of French Algeria in the absence of any German occupation" (p. 17).

${ }^{5}$ A language may give a sense of identity if it forms part of the speaker's reality. For Derrida, not only did French not represent his Algerian reality, such tongue became the language that, along with its culture, made him feel as an outcast within the compounds of his only home.
}

Language and Psychoanalysis, 2016, 5 (1), 4-13

http://dx.doi.org/10.7565/landp.v5i1.1551 
disorder of identity...I do not doubt either that such "exclusions" come to leave

their mark upon this belonging or not belonging of language, this affiliation to

language, this assignation to what we peacefully call a language (pp.16-17).

This passage describes the manner in which language, whether spoken, or written, echoes our past and thus carries within it our cultural and personal history. For Derrida, his French language became the language of trauma, the one that engulfed his history. His French belonged to those who ostracised him during tragic childhood years of oppression and overall injustice. Equally important, it was the language that linked to his identity: Derrida's French was connected to a childhood identity that became challenged the moment the author was segregated from the non-Jewish sector of the population and denied his right to be and feel French. This conflicting sentiment, the opposing connection of discrimination in the hands of his government, combined with his childhood fidelity towards his French language, culture and identity, amounted to Derrida's trauma or the "meaning of -his- obsessive act" (Freud, 1935, p. 245).

Sigmund Freud suggests that sufferers of distressing events demonstrate a fixation to the moment of the traumatic occurrence. Being unable to become released from the moment of traumatic experience makes subjects feel constantly alienated from their present and their future (pp. 242-243). Such patients, continues Freud, may produce the traumatic situation in their dreams or may, as seen with Derrida, experience the need to repeatedly describe their traumatic obsession in hopes of understanding and, or releasing themselves from such occurrence. Traumatic encounters with language and identity may not only trigger a sense of alienation, repression, obsession and confusion, in extreme cases of distress, the event of a trauma may also cause gaps of conscious memory or amnesia. As argued by Derrida:

...it is suitable here to think of tensions and the play of forces...of the generative fury of repression- amnesia...active, dynamic, powerful, something other than a mere forgetfulness. The interdiction is not negative; it does not incite simply to loss. Nor is the amnesia it organizes from the depths, in the nights of the abyss, incited to perdition. It ebbs and flows like a wave that sweeps everything along upon its shores...It carries everything ...enriches itself with everything, carries away, brings back, deports and becomes swollen again with what it has dragged away.... (Derrida, 1996, p. 31).

For Derrida, the aforementioned amnesia and repression relates to his childhood experiences. Repressing memories is an unconscious act that protects the subject against unpleasant, traumatic events. It is a build-in defence that releases the emotional tension of 
a trauma by blocking, at least part of, its conscious memory, or replacing it by falsifications (Freud, 1935, p.251). Returning to my experience, I am aware that the memory of my childhood experiences is flawed. My family often recounts childhood stories of happy and sad incidents that involved me. These are situations of which, no matter how hard I try and how much detail I am given, is never brought back to the surface of my consciousness. One aspect of my past I do remember, nonetheless, is how, as a pre-teen and a teenager, the sound of the English language was enough to trigger feelings of confusion and distress. The undeniable link between language, knowledge, relationships and identity made me openly blame the English language for my adverse circumstances. It is for this reason that for years of my life English became a language I had perceptually lost, for it was consciously forgotten.

\section{Post-Trauma}

In Argentina I eventually became proficient in Spanish and re-invented my existence. Within years of my return to Buenos Aires I was able to disguise myself as a Spanish speaker who mixed among the dominant linguistic community, without an apparent trace of a foreigner's accent and, or identity. In Argentina I repressed my memories of my Canadian life and embraced my accepted identification. In three years' time I had made a home in Buenos Aires: a home that was build upon the discontinuity and shattering of my experiences, and the rejection of anything English. Within my own linguistic exile and displacement, I became a new, distinct self that was oblivious of my own colonization, of my psyche's undertaking and thus, of the constant undercurrent that overwhelmed my being and filled my unconscious mind.

\section{Disruption of a Sense of Permanence}

I recognize that had Buenos Aires been my last city of migrations, English would have remained a severed language: a language potentially disconnected with my inner life and daily social interactions. Nonetheless, unlike subjects who may be able to consciously neglect a previous language for their entire lives, I was unwillingly made to return to Canada at the age of seventeen. Returning was an event that marked my second intrasubjective split and forced me to bring the English language back into light.

My parents' decision to migrate back to Canada was due to the economic and political crisis that existed -and still exists- in Argentina. Even though I returned to the place and the language I use to live and breathe, becoming immersed once again in its environment as a non-English speaker made me feel estranged, empty of language and disoriented. During this period of my life, I missed feeling at home with the English language and desperately tried to overcome the infantile stage of language to which I was re-subjected. Most of all, I loathed feeling lost within an environment I no longer understood. As it is for many child and adolescent migrants, during the initial stages of host-foreign language immersion I felt socially unfit in Canada and experience a despairing need to return to Argentina. During those times of re-lived strife, I clearly recall feeling as if a massive force oppressed my chest and placed me within glass walls: I could see the outside world, but without a common language, I could not participate in it. After a total of five years ${ }^{6}$,

6 Within two years I re-learned English in second language classrooms. Approximately five years following my return to Ontario, Canada I regained fluency Language and Psychoanalysis, 2016, 5 (1), 4-13 
however, my Spanish become partially replaced and I once again achieved instrumental mastery of the English language.

\section{My Present}

Glancing back at my life, I can affirm that regardless of my present immersion within the English-speaking community, my proficiency in the English language and thus, my apparent assimilation, I have not achieved a full translation. At times and depending on the group of either Spanish or English speakers with whom I interact, I notice that I often lack in both linguistic codes. Frequently, when either language makes me feel socially displaced and emptied of words, my inner self feels like an empty urn that has never been fully occupied. As an adult, I often feel that I do not have a linguistic vehicle that provides me with a sense of psychic wholeness, continuity and belonging. Looking at my past, however, the one and only language that has ever made me feel close to being whole was my childhood English, the language I spoke before my trauma. As an adult living in Canada, although English is, more often than not, my language of social function, it is still not a language of absolute comfort. As an adult, I commonly feel that I am caught between languages. I sense that although I sound native in both English and Spanish, I can never fully master either language. I still feel intimidated when I try to express myself in English spoken lectures and in uncomfortable social gatherings. At times, I get so anxious that I partially block what others say and therefore cannot produce the words or the thoughts that would allow me to engage in a cohesive argument. In addition, I dislike and sometimes struggle when I am asked to read out loud in front of a crowd in either language. I often wonder if, in part, my lack of confidence in my adult English language is consequential to the traces of negative feelings I have experienced in Argentina during the months of war. I also question if my insecurity with all language and not just English- relates to the inner struggle that exists within my psyche, a discussion I intend to turn our attention to shortly.

As for Spanish, my so-called mother tongue: the language linked to my 'earliest maternal imago' (Akhtar, 1995, p. 1069), the symbolic code of meanings that 'developed through and within my history of affect' (Carrá-Salsberg, 2015, p. 46), such language has been downgraded following my return to Canada. Its internal occupancy has become shared as part of an unstable conundrum that exists within me. What most individuals find puzzling is that although I have been teaching Spanish grammar at the postsecondary level for the past fifteen years, I find myself unable to teach Spanish to my twelve and ten year-old daughters. Even though English has been openly linked to my traumatic past, English has also become my language of love and choice with my children. It is the language of storytelling, fairy tales, dreams and deep-rooted conversations I share with my daughters and life-partner. Through my children, I am able to re-live my childhood language, the untouched, cherished symbolic code I spoke and lived before my rupture and first intrasubjective split.

The opposing effects of language are constant in our everyday lives, yet become more evident with those who suffered from language and identity related traumas. My attraction to the language of related trauma could, in part, be linked to Derrida's (1996)

in English and, when communicating in English, spoke with little, to no trace of a Spanish accent. 
feelings towards French. At the conscious level, Derrida describes his duality of resistance and, simultaneously, the obsessive attraction towards the accomplice and perpetrator of his oppression, which in his view is his own French language. According to Paulo Freire, an oppressed individual houses the oppressor -in this case the French language- by internalizing her or his rules and thus, wanting to be like -and or speak likethe oppressor (Freire, 2000, p. 48, my italics). For Derrida, his attraction to the French language is expressed in the way he tries to emulate the accent and abides by the strict grammatical rules of Parisian French, the colonizing language of the other ${ }^{7}$ :

My attachment to the French language takes forms that I consider 'Neurotic.' I feel lost outside the French language. The other languages which, more or less clumsily, I read, decode, speak, are languages I shall never inhabit. Not only am I lost, fallen and condemned outside the French language, I have the feeling of honouring and serving all idioms, in a word, of writing 'the most' or 'the best' when I sharpen the resistance to $m y$ French, the secret 'purity' of my French... (p. 56).

In Monolingualism of the Other and the Prosthesis of Origen, Derrida asserts that a mother tongue can only exist in relation to another tongue (p. 36). It is a reconstruction facilitated by the incorporation of other symbolic codes. Upon migration, subjects' language of origin becomes incompatible with their socio-linguistic reality. It encompasses, nonetheless, the memory of wholeness, comfort, belonging and linguistic fluidity individuals experienced before their linguistic rupture. Migrants' primary language becomes reconstructed as a memorial of an idealized life, as a signifier of permanence in displacement (Akhtar 2012). Such language, argues Bohorquez (2008), comes to "signify the most unalienable possession, the self-guard of self-sameness of one's sense of continuity and permanence in place and time" (p. 90).

As stated by Derrida: "We dwell on our language of origin only upon having forgotten that the language we call maternal is never purely natural, nor proper, nor inhabitable" (Derrida, 1996, p. 58). In agreement with this philosopher, the wholeness and possession of a migrant's mother tongue is an illusion. From the moment of migration the mother tongue becomes, in its incompatible, unstable nature, the language of the other, a language that often has no genuine utility or social meaning to the migrant. Throughout his book, Derrida speaks of his attraction to his mother tongue: to his language of oppression(s), an oppression that stemmed from his colonization and childhood trauma

${ }^{7}$ Derrida (1996) explains that to be a French speaker in Algeria meant to live between two cultures: that of the colonizer and that of the colonized; to want to be like the mainstream French, while belonging to the Algerian subculture. Thus Derrida explains feeling that he spoke the language of the other, while never having a mother tongue to consider as his own. In other words, French was a language that did not represent him in its entirety, even if it was his only language of genuine affiliation (pp. 30-31). 
and one that was born within his being. There are many aspects of Derrida's text worth exploring and one is the manner in which the author wrote his text. According to Bohorquez (2008), Derrida's dialogue between himself and an objector represents "the contradictions between his philosophical stance and the vestiges of his own colonial subject position" (p. 104). She suggests that in Monolingualism of the Other and the Prosthesis of Origen Derrida is expressing the internalized double bind of colonial impersonation, whereby he is expected to be similar, but never the same as his colonizer. It is a stance, according to Bohorquez, that "inevitably destines subjects to the failure of never measuring up to the ideals from which the colonial subject is structurally excluded" (p. 104). I would like to propose, moreover, that Derrida's linguistic struggle for perfection may also relate to the unnerving pressure of his superego.

According to the psychoanalyst and former adult migrant Erwin Stengel (1939), to acquire and speak a language is an achievement of the ego (p. 475). As such, speaking a language evokes on the ego a psycho-emotional sense of accomplishment or of inappropriateness, depending on the speaker's aptness or level of proficiency in the target language and on the sternness of her superego (p. 472). When expressing oneself through language, the stricter the superego adheres to the enunciation and grammatical rules of the linguistic code, the more difficult is for the ego to adjust to the emotional process of speech and, as it the case with migrants, the process of language acquisition (p. 473). Bearing this theory in mind, one may agree that subjects' sense of linguistic deficiency may in part rely on their superego's imposition of its ideals and unreasonable expectations, which, like "the double bind of colonial impersonation" (Bohorquez, 2008, p. 104), destines individuals to failure, to a sense of diffidence and possible lack of selfconfidence. In my case, living between tongues, housing the oppressor within me and speaking the language of oppression have led to my sense of general discomfort in language and eventually, to the writing of this paper.

\section{Conclusion}

Language, as we know it, has the antagonistic ability to wound and to heal. One may assume that for Derrida, his autobiographical testimony became a story of his return home. It was a testimony of healing, acceptance and understanding. In agreement with Felman and Freud, a language offers pedagogical and clinical benefits (Felman, 1991, p. 56; Freud, 1935, pp. 253-254). Writing can become a medium that carries an underlying testimony of the consequences of an emotional atrocity. It can become a 'writing cure': a vehicle that not only informs readers of harrowing occurrences, but also heals the writers from the pain, suffering and isolation inflicted by a unique, unforgettable experience.

By means of a lived symbolic code subjects are able to share their experiences in hopes of giving closure to the conflicts that stem from having lived through a trauma. In time, Derrida was able to objectify his existence within his world (Freire, 2000, p. 99), to name his word (pp. 83-88) and thus, overcome the existential situation that limited and prevented him from his ontological right to become a subject free from his haunting past (pp. 88-99, my italics). Expressing himself by means of oral and written language allowed the philosopher to critically perceive and understand his reality (Freire, 2000, p. 53) in order to translate himself.

As studied thus far, it is through language that we learn about our world, our reality and 
ourselves (Freire, 2000, p. 35). Our language moulds us as subjects and becomes part of what engages the self to the outer and inner compounds of its existence. It is a central aspect of our existence that is not immune to our possible inner and outer oppression, torments, repression, sense of otherness and pain. My particular history has left me lost in transition. Although my internal language is mostly governed by the English symbolic code, when under stress, my adult language does not grant me safety, nor does it stop me from feeling paralysed and at a loss for words. Until now I have blamed English for my socio-linguistic and emotional sense of tragedy. After writing this autobiographical testimony, however, I realize that my so-called heritage home is also to blame for my sensed strife. The culture that ostracised me for being a linguistic minority in Argentina during the months of war was not Canadian, but Argentinean. Nevertheless, being a child thrown into an overwhelmingly unfair situation made me turn against my identity and what was felt as the language of the enemy. Looking back at my reconstructed experiences between languages, it seems commonsensical to state that the anger I transferred to the language of my childhood and to my being, made me reject, replace, and eventually block English from memory. I also understand that when I lived in Argentina, being and feeling Spanish, after having successfully lost all traces of my English accent, was an artificial construction. Reclaiming my mOther tongue under my given circumstances was a gesture of hostile assimilation: a way of unknowingly becoming colonized by a language and a society that my well-intentioned parents believed were rightfully mine. I often wonder if I will eventually overcome the long-lived psycho-emotional and linguistic consequences of my experiences between languages. I recognize, nonetheless, that understanding my existential condition is a start: it is the beginning of a journey of learning, forgiving, self-acceptance, liberation and ultimately, of a much desired translation and sense of home.

\section{Biographical Note}

Fernanda Carrá-Salsberg has been a postsecondary foreign language educator for the past fifteen years. Born in Buenos Aires, Argentina, her interest in language, culture, migration, trauma and identity formations stems from her repeated migrations as a child and an adolescent, and from experiences as a language pedagogue. She has taught English as a Second language and Spanish. Carrá-Salsberg is currently teaching elementary and intermediate Spanish Grammar and Spanish for Native Speakers at York University, Ontario, Canada.

Carrá-Salsberg has obtained a Bachelor of Arts Degree with Honours in Spanish Language, Literature and Linguistics at York University, a Bachelor of Education Degree in Second Language Acquisition and History at the University of Toronto's Ontario Institute for Studies in Education, a Master's in Arts Degree in Spanish Language and Literature at the University of Toronto. She has also graduated with a Doctor of Philosophy Degree in Language Acquisition, Language Philosophy and Psychoanalysis from the Faculty of Education, York University. 


\section{References}

Adorno, T. (1974). Minima moralia: Reflections from a damaged life. Translated by E. F. N. Jephcott. London: New Left Books.

Akhtar, S. (1995). A third individuation: Immigration, identity, and the psychoanalytic process. Journal of American Psychoanalytic Association, 43, 1051-1084.

Akhtar, S. (2012). Strange lands: Location and dislocation: The immigrant experience. Presented at the $18^{\text {th }}$ Annual Day in Applied Psychoanalysis, Toronto, Ontario, September 15.

Bohórquez-Arcila, P. (2008). Living between languages: Linguistic exile and self translation. (Doctoral Dissertation). Toronto: York University.

Carrá-Salsberg, F. (2015). Impressions and Transformations: A Psychoanalytic Look of the effects of early linguistic disruptions, emotional trauma and testimony through the study of Oscar Hijuelos' Thoughts without Cigarettes. Language and Psychoanalysis, 4, 31-49.

Derrida, J. (1996). Monolingualism of the other and the prosthesis of origin. Stanford, CA: Sanford University Press.

Felman, S. (1992). Education and crisis, or the vicissitudes of teaching. In S. Felman \& D. Laub (Eds). Testimony: Crisis of witnessing in literature, psychoanalysis and history (pp. 1-56). New York, NY: Routledge.

Freire, P. (2000). Pedagogy of the oppressed. New York, NY: Continuum.

Freud, S. (1935). A general introduction to psychoanalysis. New York, NY: Liveright Publishing.

Freud, S. (2006). Beyond the pleasure principle. In A. Philips (Ed.), The Freud reader (pp. 132-195). New York, NY: The Penguin Group.

Pavlenko, A. (2014). The bilingual mind and what it tells us about language and thought. New York, NY: Cambridge University Press.

Stengel, E. (1939). On learning a new language. International Journal of Psychoanalysis, 20, 471-479.

Van der Kolk, B. \& Van der Hart, O. (1995). The intrusive past: The flexibility of memory and the engraving of trauma. In C. Caruth (Ed.), Trauma: Explorations in memory (pp. 151-182). Baltimore: The Johns Hopkins University Press. 